\title{
Acoustic Behavior of a Partially-Premixed Gas Turbine Model Combustor
}

\author{
Patton M. Allison ${ }^{1}$, James F. Driscoll ${ }^{2}$, and Matthias Ihme ${ }^{3}$ \\ Department of Aerospace Engineering, University of Michigan, Ann Arbor, MI 48109
}

\begin{abstract}
Combustion instabilities in gas turbine engines often give rise to acoustic resonances. These resonances occur as manifestations of different acoustic modes, of which a single or multiple modes may be present. In this work, the acoustic behavior of a model gas turbine combustor, developed at DLR Stuttgart by Meier, was investigated using both syn(thetic) gas and standard hydrocarbon fuels. Syngas displayed significantly different behavior than hydrocarbon fuels, even when the laminar flame speeds of the fuels were matched. The following operating parameters were systematically varied: equivalence ratio, air mass flow rate, burner temperature, flame speed, and fuel type. The results did not correspond to any one known instability mechanism. It is concluded that, in the current burner configuration, integrated-acoustics occur that involve a combination of mechanisms. These include organ tone resonances, Helmholtz-type instability, and convective-acoustic effects. Another possible factor is the fluid mechanical switching observed between the two swirler air passages, due to blockage caused by flame position and shape. Flame characteristics such as anchoring and liftoff height appear to play a major role in the determination of instability strength. As hydrogen content in syngas is increased, a lifted flame eventually anchors, resulting in a drastic decrease in the acoustic amplitude associated with non-resonating flames. Thus, increasing the flame speed causes two competing effects to occur. Propane acoustic data are collapsed using scaling parameters that indicate that the burner temperature and the air mass flow effects behave independently.
\end{abstract}

\section{Nomenclature}

$\begin{array}{ll}m_{a} & =\text { air mass flow rate } \\ m_{o} & =\text { reference air mass flow rate } \\ \varphi & =\text { equivalence ratio } \\ S_{L} & =\text { laminar flame speed } \\ T_{c} & =\text { burner core temperature } \\ T_{o} & =\text { reference temperature } \\ \omega & =\text { frequency }\end{array}$

\section{Introduction}

S WIRL flames impart a vital fluid mechanical effect conducive to flame stabilization through creation of a central recirculation zone and enhanced mixing. The addition of swirl to a combustor has been shown to allow stable operation over a range of conditions and regimes ${ }^{1}$. Periodic large scale motions are, in part, due to the precessing vortex core (PVC). However, swirl flames are also subject to thermoacoustic oscillations that can lead to acoustic instabilities. These instabilities arise when there is sufficient in-phase coupling between the pressure field and heat release to satisfy the Rayleigh criterion ${ }^{2}$. Previous acoustic studies typically fall into one of two categories: 1) Naturally stable flames that are externally excited at various frequencies, usually by a loudspeaker, to determine their transfer functions ${ }^{3}$ and 2) Naturally unstable flames that display intrinsic combustion instabilities ${ }^{4}$.

\footnotetext{
${ }^{1}$ Research Assistant, Department of Aerospace Engineering, AIAA Member.

${ }^{2}$ Professor, Department of Aerospace Engineering, AIAA Fellow.

${ }^{3}$ Assistant Professor, Department of Aerospace Engineering, AIAA Member.
} 
This paper focuses on a simple dual-swirl burner that undergoes a natural combustion instability at a frequency in the range between 200 to $500 \mathrm{~Hz}$. The swirl burner was developed by Meier and colleagues at DLR Stuttgart and is called the gas turbine model combustor (GTMC). It has the advantage that it is of simple design (the burner and chimney are axisymmetric) yet it contains the fundamental physics associated with gas turbine flames: it contains two swirling air streams which surround an annular fuel stream. It is known to have a naturally occurring combustion instability at $290 \mathrm{~Hz}^{5}$ for one operating condition that was reported previously where natural gas was used as the fuel. In the present work, the burner was operated on different fuels; several syngas mixtures, propane and ethylene which have very different flame speeds. The equivalence ratio, air mass flow rate and burner temperature was systematically varied, and then the frequency and amplitude of the combustion instability were measured. This generic swirl burner also has the advantage that, for one operating condition, many properties of the flow field have been carefully mapped by Meier and colleagues using PIV and PLIF diagnostics ${ }^{6}$.

However, there are still many important unanswered questions, such as what differences exist between syngas and conventional fuels when combustion instabilities are generated in a swirl flame? As well, are these differences only due to the higher flame speeds associated with the hydrogen content of syngas, or are they due to other factors? This paper does report significant differences associated with syngas. When the flame speeds were matched between one syngas mixture to that of ethylene, the syngas results varied from the hydrocarbon data.

In some experiments the frequency was found to be proportional to the acoustic speed, indicating the presence of organ tones or a Helmholtz resonance, while in other experiments the frequency scales with the flow velocity, due to a convective-acoustic mechanism. Even with the simplest types of swirl flame geometries, it is known that several types of combustion instabilities can occur simultaneously. Decruix et al. ${ }^{7}$ and Lieuwen ${ }^{8}$ offer comprehensive reviews of the subject. Rockwell ${ }^{9}$ has shown that when air flows over a cavity, tones occur at low frequencies that are proportional to the gas velocity, and not the acoustic velocity. This introduces a relevant Strouhal number. High frequency oscillations through cavities can be determined by organ tone resonances, which are speed of sound dependent. These two types of mechanisms can be coupled in a convective-acoustic mode as addressed in studies by $\mathrm{Yu}^{10}$ and Lieuwen ${ }^{11}$. Both of the references characterize an acoustic coupling between the flow velocity and a convected entropy wave. Lieuwen describes this wave as one that propagates downstream to some flow constriction; a new wave then is excited which moves upstream and impinges on the injector nozzle. He developed a simple low order model for premixed systems to describe the feedback process. Equivalence ratio fluctuations drive heat release oscillations, which, in turn, cause pressure fluctuations. Yu et al. systematically varied the combustor length and inlet velocity to show that the convection time for the reflected entropy wave explains their acoustic measurements.

A Helmholtz instability was identified in an industrial swirl burner by Zähringer et al. ${ }^{12}$ It was shown that the exhaust chimney length directly scales the observed frequency. They concluded that two mechanisms were present; one controlled by the swirler geometry and one controlled by Helmholtz resonances due to the geometries of the combustion chamber and exhaust pipe. Two independent mechanisms were observed by Samaniego et al. ${ }^{13}$ in a premixed propane-fired dump combustor when it was operated fuel-rich or fuel-lean. The dual-mode behavior of this burner was shown to be mass flow dependent and affected by fluid mechanical oscillations of the injected streams impinging upon each other. Small perturbations caused the axis of one jet to switch to be slightly to the right or the left of the other jet. This is known to cause a fluid mechanical oscillation which is sometimes called a switching effect. It was also suggested that a pressure node for a standing wave can be anchored outside of the exhaust of the burner, allowing for resonating wavelengths that are physically longer than the device. Steinberg ${ }^{14}$ has shown that the motion of the PVC along with the size of recirculation zones can act as a blockage to the flow and affect flame position. The recirculation zone can change size and location due to thermal expansion and move upstream pushing the flame upstream which leads to oscillations in equivalence ratio and air flow rate.

Syngas is one of the focal points of the present work. Previous syngas studies with swirl flames have measured the flame blowout limits but not the acoustics. Blowout limits were reported by Lieuwen et al. ${ }^{15}$, Fritz et al. ${ }^{16}$, and by Tuncer et $\mathrm{al}^{17}$. The enhanced blowout limits were attributed to higher flame speeds afforded by the hydrogen component of syngas, but this also leads to flashback problems wherever the reactants are premixed.

A major challenge in combustion research is the characterization of the causes and processes that lead to these cyclical changes in pressure and heat release. Meier et al. have led a thorough investigation on the performance of combustion dynamics ${ }^{18}$, PVC motion ${ }^{19}$, mixing ${ }^{20}$, and recirculation ${ }^{21}$ in a model gas turbine similar to the one studied in this paper, with their focus being primarily on flow-flame interactions. These studies have focused on a small subset of operating conditions using methane as a primary fuel. However, a comprehensive study has not been conducted to address the effects of equivalence ratio, flame speed, temperature, inlet velocity, or molecular weight on acoustics, particularly in partially-premixed swirling flames, as observed in this burner. Acoustic response to the parameters varied in this paper can be used to determine the mechanisms present. An integrated-acoustics model can 
be developed to describe a complex system whose thermoacoustic behavior is set by the presence of two or more of the mechanisms described above.

\section{Experimental Apparatus}

The gas turbine model combustor (GTMC), as seen in Fig. $1^{6}$, is used to study acoustic behavior and performance. The injector consists of a central air nozzle, an annular fuel nozzle, and a co-annular air nozzle. Both air nozzles supply swirling air at atmospheric pressure and temperature from a common plenum. The inner air nozzle has an outer diameter of $15 \mathrm{~mm}$ and the annular nozzle has an inner diameter of $17 \mathrm{~mm}$ and an outer diameter of $25 \mathrm{~mm}$. The measured swirl number is approximately 0.55 . Non-swirling fuel is provided through three exterior ports fed through the annular nozzle which is subdivided into $720.5 \mathrm{~mm} \times 0.5 \mathrm{~mm}$ channels. The exit plane of the central air nozzle and fuel nozzle lies $4.5 \mathrm{~mm}$ below the exit plane of the outer air annulus. The exit plane of the outer air annulus will be referred to as the injector face. The combustion chamber has a square cross section of $85 \mathrm{~mm}$ in width and $110 \mathrm{~mm}$ in height. The exit of the combustion chamber is an exhaust tube with a diameter of $40 \mathrm{~mm}$ and a height of $50 \mathrm{~mm}$. In the present investigation, the burner is operated with 3 metal blank walls and a single quartz window, with a thickness of $1.5 \mathrm{~mm}$, for flame visualization.

The burner was fired using propane, ethylene, and syngas fuels. An external cylindrical mixer was used for fuel mixing, particularly carbon monoxide and hydrogen to create syngas. This mixer allowed for the equal division of the fuel flow into three separate lines which lead to the fuel ports on the injector. Mass flow rates for the air and individual fuel lines leading to the burner were controlled by sonically choked orifices. Table 1 lists the operating parameters investigated. The hydrocarbon fuels and syngas mixtures of $20 \%$ and $25 \%$ hydrogen were burned over a range of equivalence ratios and air mass flow rates. The syngas mixture of $25 \% \mathrm{H}_{2}$ was chosen because its flame speed ${ }^{22}$ over the range $\varphi=0.65-1.0$ closely matches that of ethylene. As well, the $20 \% \mathrm{H}_{2}$ mixture matches ethylene flame $\operatorname{speed}^{23}$ from $\varphi=1.1-1.2$. Syngas gas mixtures of $30-45 \%$ hydrogen were only burned at the stoichiometric point with an air mass flow rate of $282 \mathrm{~g} / \mathrm{min}$.

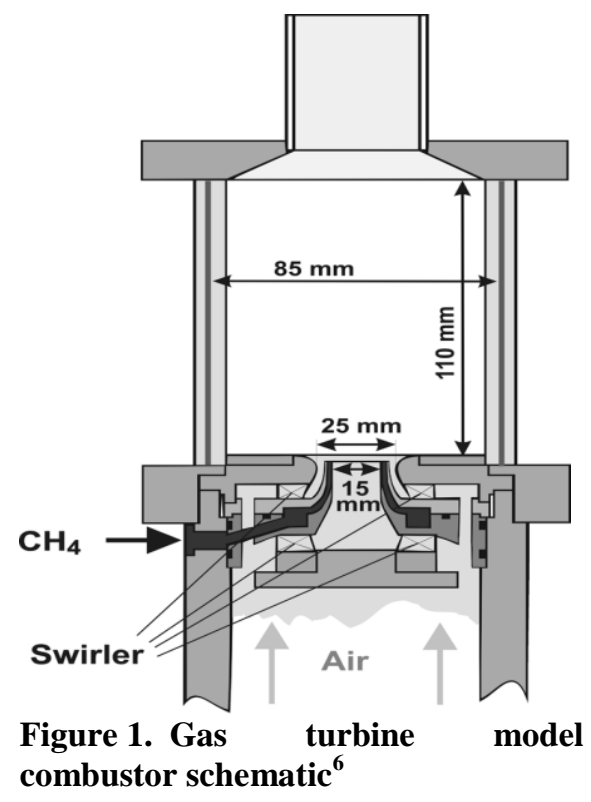

Table 1. Fueling Parameters Investigated

\begin{tabular}{ccccc}
\hline Fuel & $\mathbf{m}_{\mathbf{a}}, \mathbf{g} / \mathbf{m i n}$ & $\mathbf{\Phi}_{\text {Global }}$ & $\mathbf{T}_{\mathbf{C}}, \mathbf{K}$ & $\mathbf{S}_{\mathbf{L}}(\boldsymbol{\Phi = 1}), \mathbf{c m} / \mathbf{s}$ \\
\hline Syngas, $\mathrm{H}_{2} / \mathrm{CO}$ & & & & \\
$20 \% \mathrm{H}_{2}$ & $170-282$ & $0.75-1.2$ & $300-333$ & 60 \\
$25 \% \mathrm{H}_{2}$ & $170-282$ & $0.65-1.1$ & $300-360$ & 68 \\
$30-45 \%$ & 282 & $0.75-1.1$ & 333 & $79-100$ \\
Propane & $170-354$ & $0.65-1.2$ & $300-380$ & 65 \\
Ethylene & $170-282$ & $0.65-1.2$ & $300-380$ & 44 \\
\hline
\end{tabular}

A PCB piezoelectric transducer was used to measure the frequency performance of the burner. The transducer was located in the plenum to avoid thermal damage and wear it would undergo if it mounted on the wall of the combustion chamber. The frequency and amplitude in the plenum previously was shown to be not significantly different from that in the combustion chamber, with the exception of a phase shift $^{24}$. A thermocouple was fed into position through the plenum into one of the outer swirl vanes to measure the core burner temperature. This temperature was used as a reference point to ensure that pressure data was collected at roughly equal burner temperatures. It will be shown that there is strong correlation of the acoustic data with this reference temperature. The burner was operated continuously such that measurements could be taken at discrete burner temperatures over the ranges given in Table 1. This burner temperature more adequately reflects the temperature of the injector face over the course of a trial run, than a preheat air temperature. The temperature rises proportionally with the burner face due to heat transfer through the injector surface. The thermocouple could not be mounted exactly at the exit 
plane of the injector where it would interfere with the flame. Measurements taken with a secondary thermocouple at the end of a run, immediately after flame extinguishment, from a downstream position, indicate that the unburned air temperature at the fuel exit, $4.5 \mathrm{~mm}$ below the burner face, had risen from $300 \mathrm{~K}$ to $310 \mathrm{~K}$. Due to this small increase, it will be assumed that there will be no preheated air effects, on parameters such as flame speed, and that the core temperature is representative of the heat transfer from the flame to the burner face. The length of the swirler passage and average reported inlet velocity dictate that the residence time through the burner core is on the order of a few milliseconds. Due to this short time, the degree of air preheating is limited.

For a given equivalence ratio and air mass flow rate, pressure measurements are taken at a set temperature for 5 seconds at $20 \mathrm{kHz}$, yielding 100, 000 data points. A power spectral density (PSD) is then calculated for each data set to give frequency and amplitude data. The fluctuation strength of a resulting frequency peak is determined by integrating the PSD curve. The full width half maximum (FWHM) of each peak was typically $2-5 \mathrm{~Hz}$. This range was used as the bounds of integration around the peak. Depending on the initial conditions, acoustic frequency varied between $230 \mathrm{~Hz}$ and $500 \mathrm{~Hz}$.

Although there is no premixing within the injector, the recession of the injector facilitates partial-premixing of the reactants in the region upstream of the flame prior to combustion ${ }^{25}$. The degree of premixedness is a function of the liftoff height, fuel density and swirling velocity. The liftoff height was found to vary across fuel types and during operation of a given fuel.

\section{Results and Discussion}

\section{A. Flame Shape}

The GTMC operates in three different acoustic regimes: 1) acoustically unstable and resonating, 2) acoustically stable and non-resonating, and 3) acoustically intermittent where the flame will transition back and forth between the first two modes. This intermittent mode can be considered the marginal status between quiet and loud flames. Huang $^{26}$ and Polifke ${ }^{27}$ have studied transitioning and bi-stable flames and shown that changes in flame anchoring and shape are important in this process. The results provided in this paper do not involve intermittent cases, but will focus on acoustically unstable flames and flames that abruptly transition to non-resonating cases without reverting back to unstable.

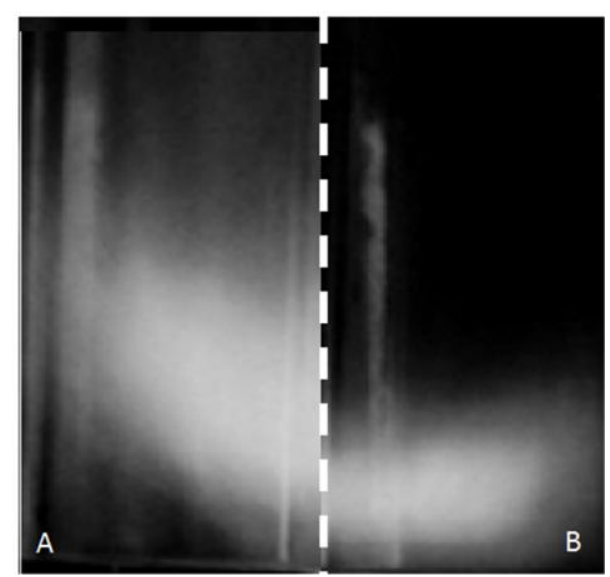

Figure 2. Average chemiluminescence of a propane a) $\mathrm{V}$-shape flame and b) flat flame.
Flame shape and anchoring play an important role in the maintenance of the instability. It was observed that the instability was amplified when the flame had a flat disk like shape that was slightly lifted. Flames that were anchored or highly lifted (light off heights less than $2 \mathrm{~mm}$ or larger than $20 \mathrm{~mm}$ ) were generally quieter. Those flames that were directly anchored to the fuel annulus or lifted several centimeters were generally non-resonating. Within the unstable resonating mode, two types of shape fluctuations were observed. The first type involved a flame liftoff height oscillation where the flame would move up or downstream. The second motion was a change from a flat disk shape to a $\mathrm{V}$-shape flame, with varying degrees in between. Figure 2 demonstrates the difference between a flat and $\mathrm{V}$-shaped propane flame.

Steinberg ${ }^{14}$ has shown that the flame height oscillations are due piston-like pumping of the PVC and recirculation zones. The change in flame shape has been observed to be correlated with the bifurcation of air flow rate through each swirler. Nominally, the mass flow ratio between the outer and inner swirler is 1.5. However, when coupled with the flame blockage and pressure fluctuations, the air flow can be redistributed. A side experiment was conducted to evaluate the flame shape change when the entire air flow was redirected through only a single swirler. When the outer swirler is blocked and flow is directed through the central nozzle, the flame is V-shaped and quieter than the nominal flame. When the inner swirler is blocked, the flow passes through only the outer swirler. Due to the curved lip of injector at the outer swirler, a large radial velocity is imparted to the flow, which is conducive to stabilizing a flat flame. It can be inferred from flame observations during trials, that changes in flame shape as described are the result of some degree of flow redistribution. 


\section{B. Equivalence Ratio Variation}

Figure 3 shows the measured frequency and amplitude response of the pressure oscillation with varying equivalence ratios. The equivalence ratio reported here is a global value, since at the inlet there is no premixing. However, it is expected that once the gases leave the injector there will be some degree of premixing over the liftoff height. The frequency response generally increases with equivalence ratio, except for propane which shows a decrease in frequency beyond $\varphi=1$. This type of behavior suggests that the frequency of the instability scales with the flame speed. However, the syngas flames display additional complications. The 25\% syngas mixture matches the ethylene data only at $\varphi=0.75$ and $\varphi=$ 1. The fuel-rich ethylene data does not match the $20 \%$ syngas data, which have the same flame speed. This also suggests that another parameter, in addition to flame speed, controls the acoustic performance. The dip in $25 \% \mathrm{H}_{2}$ frequency at $\varphi=0.85$ is interesting because it marked a change in the type of oscillation instability observed. Most of the syngas cases experience flame height oscillations, but this case resulted in flame shape oscillations.

The amplitude behavior with equivalence ratio shows varying trends with each fuel. Propane shows a decrease in instability strength, while ethylene flames resonate more powerfully with increasing equivalence ratio. Both syngas mixtures show little variation in strength. It is evident that these behaviors are not all consistently scaled with the increase in global heat release.

\section{Air Mass Flow Rate Variation}

Instabilities that are of convective-acoustic type display a frequency that varies with the gas velocity, while those that are pure organ tones or Helmholtz types do not. The air mass flow rate was varied, but the axial velocities in the inner and outer air streams were not measured. However, it is unknown if the swirler distribution is maintained as the total flow rate is increased. If a new distribution is achieved, there would be a disproportional change in the axial or radial velocity as set by the inner and outer swirlers respectively. Figure 4 indicates that the frequency of the instability increases with an increase in the mass flow rate. This suggests that the instability depends on a Strouhal number and that it contains a convective-acoustic component. The frequency data in Fig. $4 \mathrm{a}$ are similar for the syngas $\left(25 \% \mathrm{H}_{2}\right)$ and ethylene, which have the same flame speeds. The relationship between these two fuels also may have similar anchoring and mixing properties for
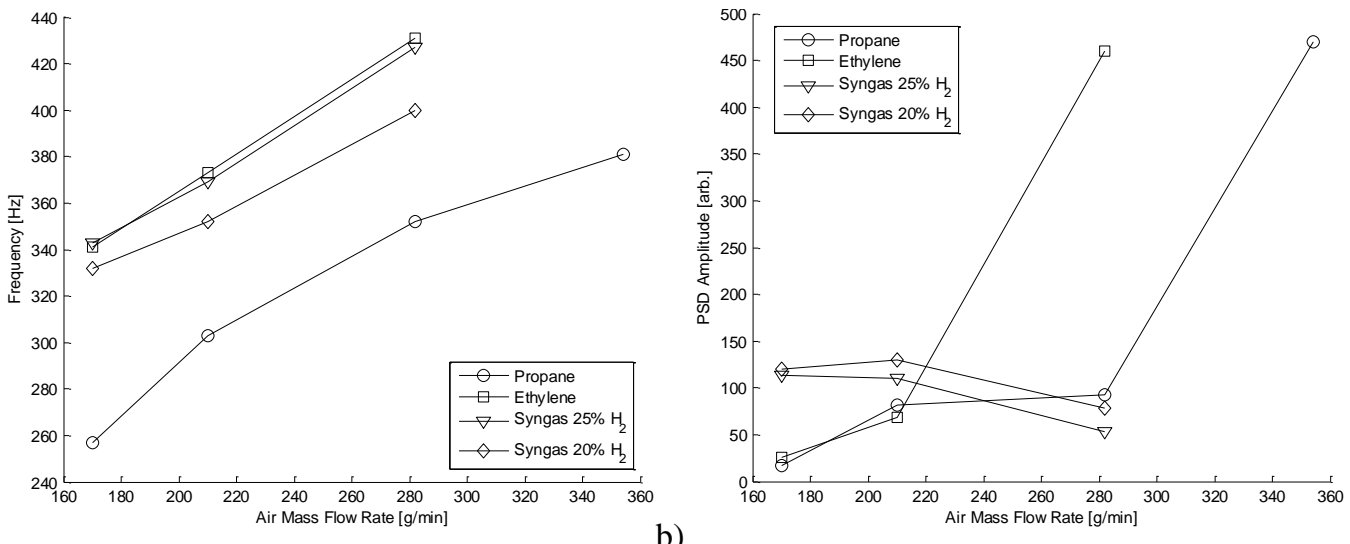

Figure 4. a) Frequency as a function of air mass flow rate for $\varphi=1$ and $T_{C}=333 K$, b) PSD amplitude as a function of air mass flow rate for $\varphi=1$ and $T_{C}=333 \mathrm{~K}$.

$$
5
$$

American Institute of Aeronautics and Astronautics
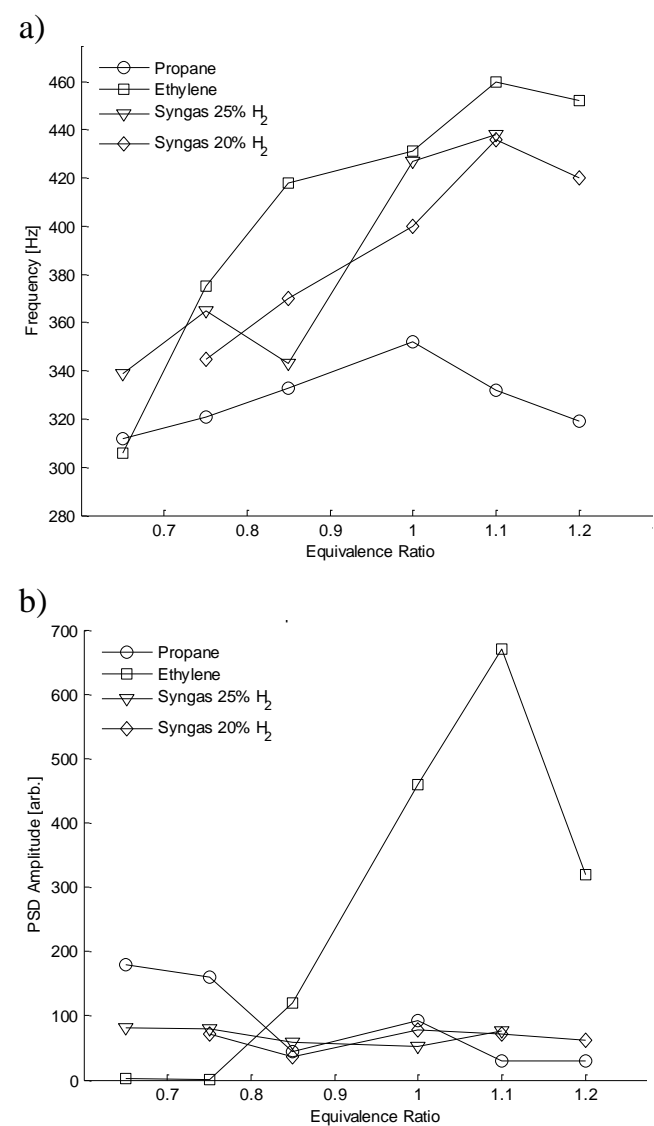

Figure 3. a) Frequency as a function of equivalence ratio for $m_{a}=282 \mathrm{~g} / \mathrm{min}$ and $\mathbf{T}_{\mathrm{C}}=333 \mathrm{~K}$, b) PSD amplitude as a function of equivalence ratio for $m_{a}=\mathbf{2 8 2}$ $\mathrm{g} / \mathrm{min}$ and $\mathrm{T}_{\mathrm{C}}=333 \mathrm{~K}$. 
the inlet conditions portrayed in Fig 4.

The amplitude data for the syngas and the hydrocarbon fuels are very different. While syngas drops in amplitude strength, thermoacoustic instabilities are amplified at higher flow rates for hydrocarbon fuels. In comparison to hydrocarbons, the lift-off height is reduced for syngas mixtures. When this effect is combined with higher inlet velocities and the high diffusivity of hydrogen, reduced mixing can occur. The nominal flame shape is also different between the types of fuels presented. The hydrocarbon flames are typically observed to be flat, whereas the synfuel flames have a wide V-shape, which tends to make them quieter.

\section{Syngas Composition Variation}

The frequency at a given equivalence ratio is independent of the hydrogen concentration as seen in Fig 5. Along this line of constant frequency, the molecular weight of the mixture decreases and the flame speed increases with increasing hydrogen content until a hard cutoff occurs in which the instability is rendered inactive and becomes non-resonating. The concentration at which this "quiet" limit occurs is equivalence ratio dependent, but the limit is extended for richer flames. Within the range of equivalence ratios considered, the maximum cutoff occurs near $43 \% \mathrm{H}_{2}$. Transitions such as these were observed in the hydrocarbon fuels, but these shifts were correlated with the swirler switching mechanism and dramatic flame shape changes. As well, this shift is quasi-stable for syngas, where once the flame is non-resonating, it will not transition back to unstable. Hydrocarbon fuels can display intermittent behavior where resonant transitioning can occur.

The amplitude of the dominant pressure signal is not equivalence ratio independent. As the "quiet" limit is approached, the instability strength is reduced until silent. This type of behavior suggests that thermoacoustic instabilities can be reduced by increasing the hydrogen content of the fuel. By also operating fuel-lean, the amount of hydrogen required to silence the flame is reduced. The data also suggests that a critical combination of flame speed and fuel density controls the acoustics for syngas. A stable syngas flame is directly attached to the burner and has a steep V-shape. A directly attached flame will have poorer mixing, resulting in a longer flame. Flat flames are acoustically compact and concentrate heat release in a smaller portion of the burner than an axially extended V-flame. Thus, V-flames are less efficient at applying thermal energy toward acoustic amplification

A Rayleigh index was calculated according to the method described by Pun et $\mathrm{al}^{28}$ for resonating and nonresonating syngas flames. Figure 6 depicts the Rayleigh index field alongside chemiluminescence images of each respective flame. Rayleigh indices greater than zero represent thermo-acoustically amplified flames where the pressure field and heat release are in phase, and indices less than zero represent regions with dampening. If the index is very small or near zero, the flame is stable and neutral. Figures $6 \mathrm{a}$ and $6 \mathrm{~b}$ show the Rayleigh index and the corresponding flame profile for a non-resonating syngas flame. The index field is populated by values that are close to zero or slightly negative which is indicative of a field with little coupling between the pressure and heat release. Figures $6 \mathrm{c}$ and $6 \mathrm{~d}$ display the same characteristics for an unstable, resonating flame and there exists a strong region of amplification surrounded by dampened regions. This result is similar to that shown by Kang et $\mathrm{al}^{3}$ in a low swirl combustor. There are noticeable differences in the flame shapes between the resonating and stable syngas flames. The stable flame shows better anchoring and has an axially extended, V-shape profile. While the unstable syngas flame is not as flat as the propane flame shown in Fig. $2 b$, its profile is wider at its base than the stable syngas flame, which implies a higher degree of premixing. The change in flame shape may also be attributed to the swirler switching mechanism. An increase in the flow rate through the central nozzle will lead to a higher axial velocity and a longer V-shape flame. Higher flow rate through the outer swirler will support a flat flame with enhanced mixing.

6

American Institute of Aeronautics and Astronautics 

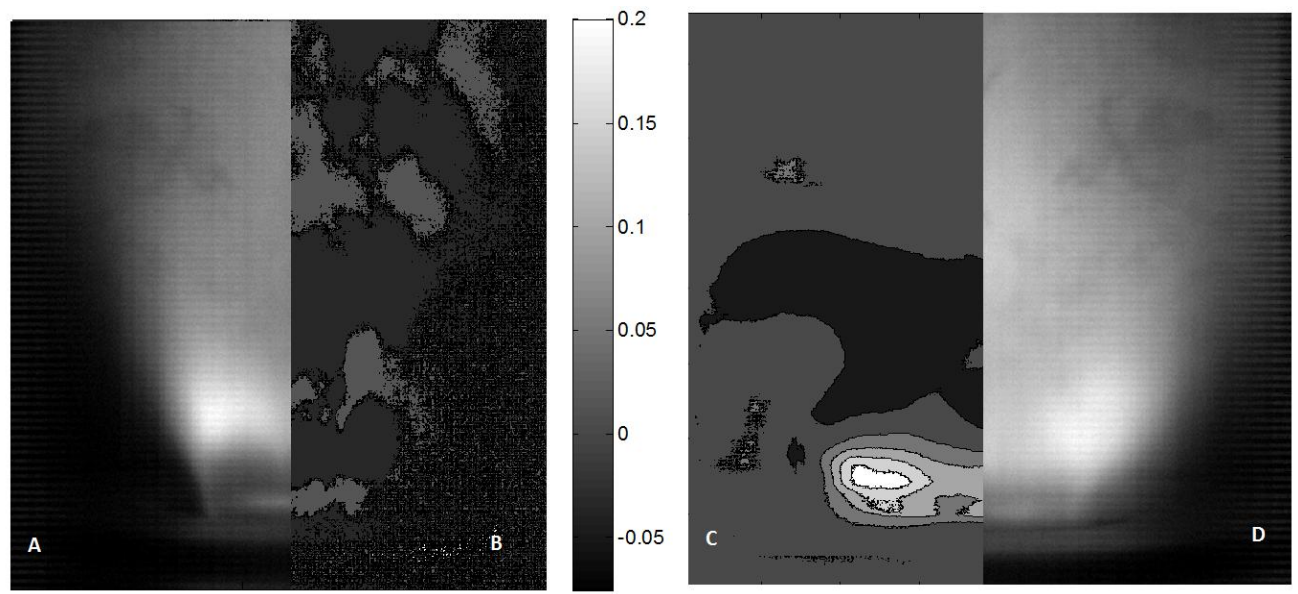

Figure 6. Rayleigh index and chemiluminescence of syngas flames. (a,b) Stable flame, $40 \%$ hydrogen for $\varphi=1, \mathrm{~m}_{\mathrm{a}}=282 \mathrm{~g} / \mathrm{min}$. (c,d) Unstable resonating flame, $25 \%$ hydrogen for $\varphi=$ $1, \mathrm{~m}_{\mathrm{a}}=282 \mathrm{~g} / \mathrm{min}$.

\section{E. Temperature Variation}

Figure 7 displays the frequency and amplitude response to variations in burner temperature for air mass flow rates of $210 \mathrm{~g} / \mathrm{min}$ and $282 \mathrm{~g} / \mathrm{min}$. As discussed previously, this temperature is representative of the injector face temperature, not the air preheat temperature. By the end of a trial run, the measured temperature has risen to $380 \mathrm{~K}$, but the air temperature has only increased to $310 \mathrm{~K}$. The air temperature in the combustor is relatively constant while the injector temperature increases as the chamber temperature increases. The frequency of each fuel type increases with temperature which is indicative of a change in the speed of sound in the product gases. Organ tone and Helmholtz resonances both scale with the speed of sound. The low flow rate ethylene case does not exhibit any pronounced temperature variation. With this exception, the magnitude of the temperature gradient in maintained for each fuel type, i.e. all syngas-mixtures considered have approximately the same slope and the hydrocarbons behave similarly.

The amplitude response to temperature variation displays several trends. The lower flow rate cases do not vary greatly over the temperature range studied. For all flow rates, the syngas amplitudes do not vary greatly. Ethylene displays a drop in amplitude strength at $345 \mathrm{~K}$ because of an observed frequency shift phenomena. This type of event was only seen to occur in hydrocarbon fuels as the burner temperature increased and only occurred for a small
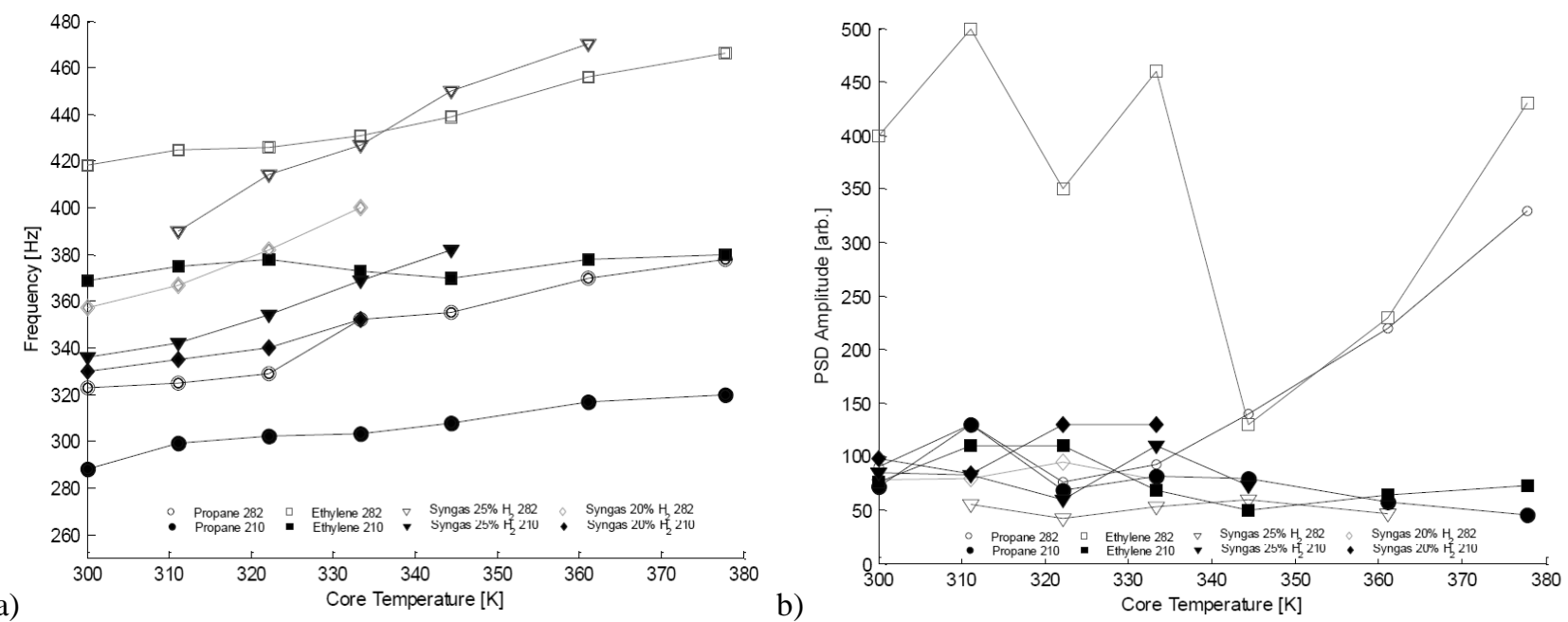

Figure 7. a) Frequency variation as a function of burner core temperature for $\varphi=1, \mathrm{~m}_{\mathrm{a}}=\mathbf{2 8 2} \mathrm{g} / \mathrm{min}^{\mathrm{and}}$ for $\mathrm{ma}$ $=210 \mathrm{~g} / \mathrm{min}$. b) PSD amplitude as a function of burner core temperature for $\varphi=1, \mathrm{~m}_{\mathrm{a}}=282 \mathrm{~g} / \mathrm{min}$ and for $\mathrm{m}_{\mathrm{a}}=$ $210 \mathrm{~g} / \mathrm{min}$. 
subset of the test conditions studied. In general, a single strong pressure peak was seen in each of the PSD plots. When the frequency shift occurred, a secondary pressure peak, shifted 20-30 Hz higher, begins to grow as the temperature increased. As this peak grew in strength, the amplitude of the original peak is reduced. At higher temperatures, the secondary peak became the dominant frequency and grew in power as the original peak died off, as observed by the rise in amplitude for temperatures greater than $345 \mathrm{~K}$.

\section{F. Flame Speed and Molecular Weight Variation}

Figure 8 shows the relationship between the observed frequency and the flame speed of a given mixture at all studied equivalence ratios for $\mathrm{m}_{\mathrm{a}}=282 \mathrm{~g} / \mathrm{min}$ and $\mathrm{T}_{\mathrm{C}}=333 \mathrm{~K}$. Flame speed data for propane were acquired from $\mathrm{Yu}^{29}$. A linear relationship between frequency and flame speed can be seen. However, the slope of each curve differs, thus each fuel behaves in different manner. Flame speed affects several things: the liftoff height, the speed at which the flame flashes back after it is forced to move downstream, and the flame shape. Within the range of equivalence ratios studied, syngas mixtures above $43 \%$ hydrogen are non-resonating, which implies that flame speeds above $110 \mathrm{~cm} / \mathrm{s}$ result in quiet flames in this burner.

a)

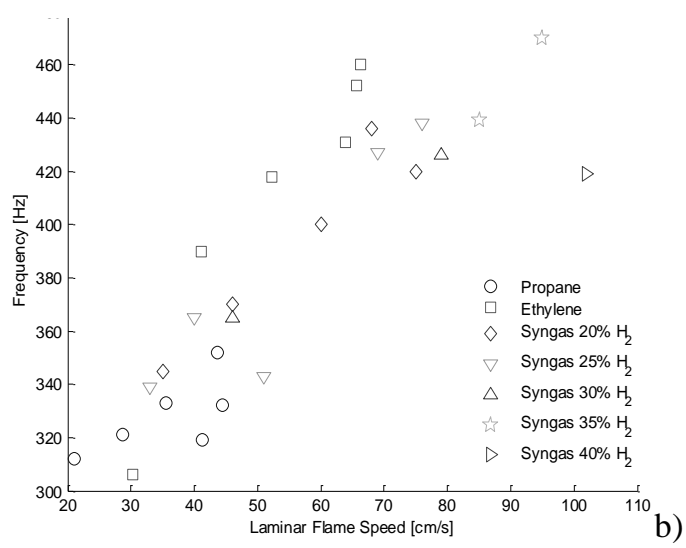

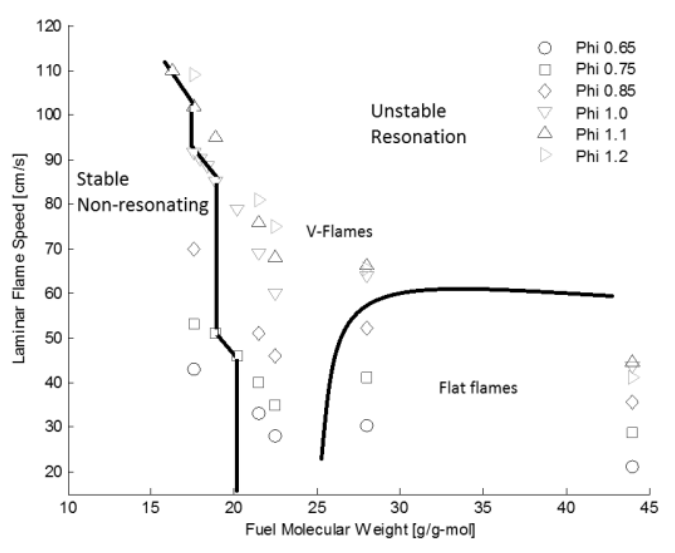

Figure 8. a) Frequency as a function of flame speed for all fuel mixtures studied at $\mathbf{m}_{\mathrm{a}}=\mathbf{2 8 2} \mathrm{g} / \mathrm{min}, \mathbf{T}_{\mathrm{C}}=$ 333K, for varying $\varphi=0.65-1.2, b)$ Regime diagram of flame speed versus fuel molecular weight for $\mathrm{m}_{\mathrm{a}}=$ $282 \mathrm{~g} / \mathrm{min}, \mathrm{T}_{\mathrm{C}}=333 \mathrm{~K}$ divided in regions of stable and unstable flames, and unstable flame shape. Vertical groupings indicate a single fuel type or syngas mixture.

Figure $8 \mathrm{~b}$ is a regime diagram depicting the relationship between flame speed and fuel molecular weight for the mixtures studied at $m_{a}=282 \mathrm{~g} / \mathrm{min}$ and $\mathrm{T}_{\mathrm{C}}=333 \mathrm{~K}$. Each series of symbols represents a constant equivalence ratio and each vertical sorting of data points refers to a single fuel mixture at a given weight, e.g. propane has a molecular weight of $44 \mathrm{~g} / \mathrm{mol}$. The diagram is sub-divided into two regimes characterized by either quiet stable flames or loud flames experiencing a thermoacoustic instability. The "quiet" limit lies along a vertical line of slightly varying fuel weight. For heavier syngas mixtures, the limit occurs at leaner conditions. Under the range of equivalence ratio observed, there is a limit at $110 \mathrm{~cm} / \mathrm{s}$. The limit may also be extended for lighter fuels if conditions richer than $\varphi=$ 1.2 are studied. Propane and ethylene fuels are unstable for all the conditions studied at the given flow rate.

The molecular weight of the fuel appears to play a role in the acoustic behavior, based on Fig. 8b, but the specific mechanism is not yet known. Several fuel-air mixtures studied have the same flame speed of $45 \mathrm{~cm} / \mathrm{s}$, yet they exist in very different regimes in Fig. 8b. Molecular weight is known to control thermo-diffusive instabilities in flames which could play a role in the acoustic instability-mechanisms that were studied, as suggested by the present data. A different diagram can be assembled for lower flow rates where the "quiet" limit would occur at heavier weights and lower flame speeds. Similarly, the temperature dependence of these fuels can also affect the location of the stabilizing limit. The unstable regime has been divided into the type of observed flame shape. Propane and lean ethylene yield flat flames, while all the syngas mixtures yield V-shaped flames.

\section{G. Parameter Scaling}

For propane, a scaling model, as given by Eq. 1, has been determined based on the burner temperature and air mass flow rate. The scaling parameter for each variable, $\mathrm{n}$ and $\mathrm{p}$, was calculated by a least square minimization method. This minimization was done independently for the two parameters with reference to a mass flow rate of 282 $\mathrm{g} / \mathrm{min}$ and $311 \mathrm{~K}$. The resulting values of $\mathrm{n}$ and $\mathrm{p}$ were $0.51 \pm 0.02$ and $0.34 \pm 0.01$, respectively. The very narrow uncertainties in these values indicate that burner temperature and air mass flow rate act independently in 
determining the frequency of the instability. Figure 9 depicts the scaled frequencies over the entire range of equivalence ratios. The original data set contained frequencies over a wide range from $230 \mathrm{~Hz}$ to $380 \mathrm{~Hz}$, while the scaled data nearly collapses to a single curve, with variations less than $10 \%$.

$$
\omega=\left(\frac{T_{C}}{T_{0}}\right)^{n}\left(\frac{\dot{m}_{A}}{\dot{m}_{0}}\right)^{p} f(\varphi)
$$

The scaling of frequency with the $T^{1 / 2}$ is indicative of a change in the speed of sound in the combustion chamber. Changes in the speed of sound can result in frequency changes in organ tone and Helmholtz modes. However, the frequency also is proportional to $m_{A}{ }^{1 / 3}$, which indicates that a convective-acoustic mode also is present.

\section{H. Burner Configuration Variations}

The dimensions of the GTMC combustion chamber, exhaust tube, and plenum were varied to investigate Helmholtz and organ tone behavior. Table 2 summarizes the dimensions varied and the percent change from the nominal frequency of $320 \mathrm{~Hz}$ for a propane flame operated at $\varphi=0.75, \mathrm{~m}_{\mathrm{a}}=282 \mathrm{~g} / \mathrm{min}$, and $\mathrm{T}_{\mathrm{C}}=333 \mathrm{~K}$, for the standard burner configuration. When the combustion chamber length was varied from 75 to $300 \mathrm{~mm}$, no frequency shift larger than $10 \%$ was observed. This result indicates that a standing quarter wave, which scales with combustor length, is not present. The combustor diameter was reduced to $50 \mathrm{~mm}$ resulting in an $11 \%$ shift to a lower frequency. The volume of the plenum was also varied to determine if an organ tone or Helmholtz resonance is associated with its dimensions. There was a negligible frequency change.

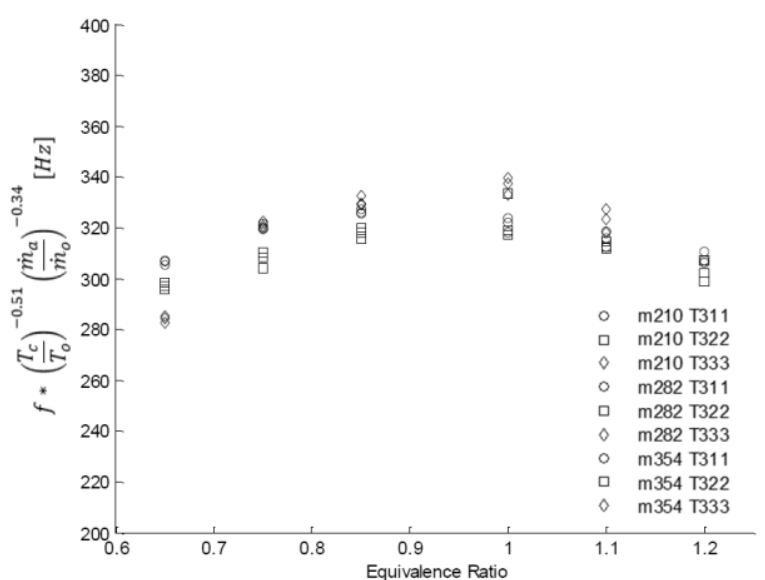

Figure 9. Propane frequency rescaled by temperature and air mass flow rate for $m_{a}=210-354 \mathrm{~g} / \mathrm{min}, T_{C}=$ 311- 333K. $T_{0}=311 \mathrm{~K}$ and $\mathrm{m}_{0}=282 \mathrm{~g} / \mathrm{min}$.

The largest frequency changes were observed in changes involving the exhaust tube. Increasing the tube length by $460 \%$ caused the frequency to shift by $64 \mathrm{~Hz}$. When the exhaust pipe was removed, the frequency was also downshifted by $23 \%$. Changing the diameter of the exhaust pipe resulted in a smaller change to the frequency, but a large increase in the amplitude of the instability was observed. If lumped-acoustic mode ${ }^{30}$ for a Helmholtz resonator is considered, the results suggest that the exhaust pipe length and diameter may play a role in changing the impedance of the system.

Table 2. GTMC configurations investigated for propane fuel at $\varphi=0.75, \mathrm{~m}_{\mathrm{a}}=282 \mathrm{~g} / \mathrm{min}$, and $\mathrm{T}_{\mathrm{c}}=333 \mathrm{~K}$.

\begin{tabular}{ccc}
\hline Component & Variation & $\begin{array}{c}\text { Frequency Change } \\
(\% \text { change from 320 } \mathbf{H z})\end{array}$ \\
\hline Chamber & $75-300 \mathrm{~mm}$ & $<10 \%$ \\
Length & Decrease to $50 \mathrm{~mm}$ & $11 \%$ Decrease \\
Diameter & & \\
Exhaust Tube & Increase to $230 \mathrm{~mm}$ & $20 \%$ Decrease \\
Length & Remove Tube, $0 \mathrm{~mm}$ & $23 \%$ Decrease \\
Length & Decrease to $13 \mathrm{~mm}$ & $10 \%$ Decrease \\
Diameter & & \\
$\begin{array}{c}\text { Plenum } \\
\text { Volume }\end{array}$ & Decrease Volume $33 \%$ & $<5 \%$ \\
\hline
\end{tabular}




\section{Conclusion}

The GTMC studied exhibits a wide range of acoustic behaviors, which can correspond to a number of active and coupled acoustic modes. The frequencies and amplitudes of a combustion instability were measured while the following operating parameters were systematically varied: equivalence ratio, air mass flow rate, air temperature, flame speed, and fuel type. Syngas displayed significantly different behavior than hydrocarbon fuels, even when the laminar flame speeds of the fuels were matched. Flame speed was found to play an important role since it affects both the frequency and amplitude of the instability. This trend indicates that either the flame liftoff height or some type of flashback oscillation is important, since flame speed should not affect the frequency of a pure Helmholtz or organ tone resonance. The air velocity also affected the frequencies and amplitudes, indicating that a convectiveacoustic mechanism plays a role. The geometry of the exhaust pipe greatly affected the acoustic amplitude, indicating that some sort of driven Helmholtz resonance is present. Finally, it was observed that flow switching occurs; the total air flow rate was fixed but the fraction of air passing through the inner and other annular passages changes. Switching of air flow between the two air passages was caused by blockage induced by the flame position and shape. Figure 10 depicts simple, low order feedback ideas that link together the important flame-fluid relationships. The details of how the different factors in Fig. 10 are linked together are still being studied. It is concluded that the instability cannot be due to one single mechanism but is due to integrated-acoustics involving a combination mechanisms, including Helmholtz, convective-acoustic, and perhaps fluid mechanical switching.

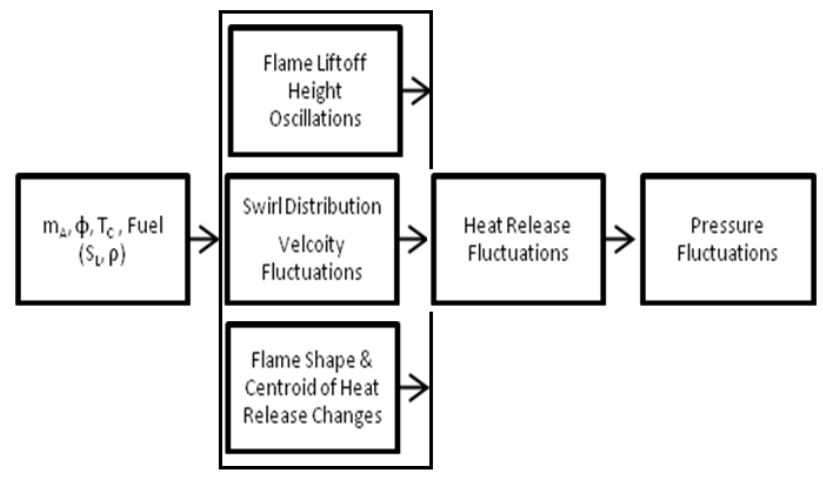

Figure 10. Proposed feedback system of thermoacoustic relationships.

\section{Acknowledgments}

This research was funded by ONR under grant N00014-10-10561 and by the DOE-UTSR program under grant FE0007060. The authors thank Dr. Wolfgang Meier of DLR Stuttgart for permission to use the gas turbine model combustor design that he and his colleagues developed at DLR.

\section{References}

\footnotetext{
${ }^{1}$ Gupta, A.K., Lilley, D.G., and Syred, N., Swirl Flows, Abacus Press, Kent, 1984.

${ }^{2}$ Lord Rayleigh, Notices of the proceedings meetings members of the Royal Institution of Great Britain VIII, $1878,536-542$.

${ }^{3}$ Kang, D.M., Culick, F.E.C., and Ratner, A., "Combustion dynamics of a low-swirl combustor", Combust. Flame, 151, 2007, p. $412-425$.

${ }^{4}$ Dhanuka, S.K., Temme, J.E., and Driscoll, J.F., "Lean- limit combustion instabilities of a lean premixed prevaporized gas turbine combustor", Proceedings of the Combustion Institute, 33, 2011, p. 2961 - 2966.

${ }^{5}$ Giezendanner, R., Weigand P., Duan X.R., Meier W., Meier, U., and Aigner M., "Laser-based investigations of periodic combustion instabilities in a gas turbine model combustor", J. Eng. Gas Turb. Power, 127, 2005, p. 492 - 496.

${ }^{6}$ Weigand P., Meier W., Duan X.R., Stricker W., and Aigner M., "Investigations of swirl flames in a gas turbine model combustor I. Flow field, structures, temperature, and species distributions", Combust. Flame, 144, 2006, p. 205-224.

${ }^{7}$ Decruix, S., Schuller, T., Durox, D., and Candel, S., "Combustion dynamics and instabilities: elementary coupling and driving mechanisms", J. Propulsion and Power, 19, 5, 2003,p. 722-734.

8 Zinn, B.T. and Lieuwen, T., "Combustion instability: basic concepts", Combustion Instabilities in Gas Turbine Engines, AIAA, 2005.

${ }^{9}$ Rockwell, D. and Naudascher, E., "Review - Self-sustaining oscillations of flow past cavities”, J. Fluids Eng., 100, 1978, p. $152-165$.
} 
${ }^{10} \mathrm{Yu}$, K.H., Trouve, A., and Daily, J.W.," Low-frequency pressure oscillations in a model ramjet combustor", J. Fluid Mech, 232, 1991, p. 47-72.

${ }^{11}$ Lieuwen, T., Torres, H., Johnson, and C., Zinn, B.T., "A mechanism of combustion instability in lean premixed gas turbine combustors", J. Eng. Gas Turb. Power, 123, 2001, p. 182 - 189.

${ }^{12}$ Zähringer, K., Durox, D., and Lacas, F., "Helmholtz behavior and transfer function of an industrial fuel swirl burner used in heating systems", Intl J. Heat Mass Transfer, 46, 2003, p. 3529 - 3548.

${ }^{13}$ Samaniego, J.M., Yip, B., Poinsot, T., and Candel, S., "Low-frequency instability mechanisms in a side-dump combustor", Combust. Flame, 94, 1993, p. $363-380$.

${ }^{14}$ Steinberg, A.M., Boxx, I., Stöhr, M., Carter, C.D., and Meier, W., "Flow-flame interactions causing acoustically coupled heat release fluctuations in a thermo-acoustically unstable gas turbine model combustor", Combust. Flame, 157, 2010, p. 22502666.

${ }^{15}$ Lieuwen, T, McDonell, V., Santavicca, D., and Sattelmayer, T., "Burner development and operability issues associated with steady flowing syngas fired combustors”, Combust. Sci. and Tech., 180, 2008, p. 1169-1192.

${ }^{16}$ Fritz, J., Kroner, M., and Sattelmayer, T., "Flashback in a swirl burner with cylindrical premixing zone", J. Eng Gas Turb Power, 126, 2004, p. 276-283.

17 Tuncer, O., Acharya, S., and Uhm, J.H., "NOx and flashback characteristics of confined premixed hydrogen enriched methane flames", Int. J. of Hydrogen Energy, 34, 2009, p. 496-506.

${ }^{18}$ Boxx, I., Stöhr, M., Carter, C., and Meier, W., "Temporally resolved planar measurements of transient phenomena in a partially premixed swirl flame in a gas turbine model combustor", Combust. Flame, 157, 2010, p. 1510 - 1525.

${ }^{19}$ Stöhr, M., Sadanandan, R., and Meier, W., "Phase-resolved characterization of vortex flame interaction in a turbulent swirl flame", Exp. Fluids, 51, 2011, p. 1153-1167.

${ }^{20}$ Meier, W., Boxx, I., Stöhr, M., and Carter, C.D., "Laser based investigations in gas turbine model combustors", Exp. Fluids, 49, 2010, p. $865-882$.

${ }^{21}$ Duan X.R., Meier W., Weigand P., and Lehmann, B., "Phase-resolved laser Raman scattering and laser Doppler velocimetry applied to periodic instabilities in a gas turbine model combustor", Applied Physics B: Lasers and Optics, 80, 2005, p. 389-396.

${ }^{22}$ Dong, C., Zhou, Q., Zhao, Q., Zhang, Y., Xu, T., and Hui, S., “ Experimental study on the laminar flame speed of hydrogen / carbon monoxide / air mixtures", Fuel, 88, 2009, p. 1858 - 1863.

${ }^{23}$ Kumar, K., Mittal, G., Sung, C-J., and Law, C.K., " An experimental investigation of ethylene/ $\mathrm{O}_{2} /$ diluents mixtures: laminar flame speeds with preheat and ignition delays at high pressures", Combust. Flame, 153, 2008, p. 343 - 354.

${ }^{24}$ Sadanandan, R., Stöhr, M., and Meier, W., "Flowfield-flame structure interactions in an oscillating swirl flame", Combustion, Explosion, and Shock Waves, 45, 2009, p. 518 - 529.

${ }^{25}$ Meier W., Duan X.R., and Weigand P., "Reaction zone structures and mixing characteristic of partially premixed swirling $\mathrm{CH}_{4} /$ air flames in a gas turbine model combustor", Proceedings of the Combustion Institute, 30, 2005, p. 835 - 842.

${ }^{26}$ Huang, Y. and Yang, V., "Bifurcation of flame structure in a lean-premixed swirl-stabilized combustor: transition from stable to unstable flame", Combust. Flame, 136, 2004, p. 383 - 389.

27 Polifke, W., Fischer, A., and Sattelmayer, T., "Instability of a premix burner with nonmonotonic pressure drop characteristic", J. Eng Gas Turb Power, 125, 2003, p. 20 - 27.

${ }^{28}$ Pun, W., Palm, S.L., Culick, F.E.C, "Combustion dynamics of an acoustically forced flame”, Combust. Sci. and Tech., 175, 2003, p. 499-521.

${ }^{29} \mathrm{Yu}$, G., Law, C.K., and Wu, C.K., "Laminar flame speeds of hydrocarbon + air mixtures with hydrogen addition", Combust. Flame, 63, 1986, p. 339 - 347.

${ }^{30}$ Kinsler, L.E., Frey, A.R., Coppens, A.B., Sanders, J.V., Fundamentals of Acoustics, John Wiley \& Sons, Inc., 2000 , p. 272. 